See Article page 2218.

\section{Commentary: Slide tracheoplasty: The power of numbers}

\author{
Carl L. Backer, MD
}

I am sure that when Peter Goldstraw and Victor Tsang first reported the slide tracheoplasty procedure in 2 patients, they never would have imagined a series of 120 patients accumulated over a 10 -year period! ${ }^{1}$ That is the patient population reported by the pediatric cardiothoracic team at Shanghai Children's Medical Center in this issue of the Journal of Thoracic and Cardiovascular Surgery. ${ }^{2}$ Their hospital is now the largest treatment center for children with congenital tracheal stenosis in China.

The results are quite remarkable and truly speak to the power of regionalization and the volume/outcome equation. The high volume has led to superb outcomes. The overall mortality rate was $5 \%$ and the reoperation rate was $5 \%$. The mortality dropped from $12.5 \%$ at the start of the series to $2.7 \%$ in the past 4 years. The mean time to extubation was 3 days, mean stay in the intensive care unit was 8 days, and mean hospital stay was 22 days. Nearly all of the patients had follow-up computed tomography imaging demonstrating an increase in the luminal diameter of the trachea from a mean of $2.3 \mathrm{~mm}$ to a mean of $5.5 \mathrm{~mm}$. The authors also report the results of pre- and postoperative pulmonary function studies. Their high volume of slide tracheoplasty procedures has led to excellent results.

The authors confirm what other reports have shown regarding the coexistence of pulmonary artery sling and intracardiac anomalies in these patients. Of these patients, $72 \%$ had a pulmonary artery sling and $33 \%$ had a significant intracardiac anomaly. The authors recommend

\footnotetext{
From the Section of Pediatric Cardiothoracic Surgery, UK HealthCare Kentucky Children's Hospital, Lexington, Ky; and Cardiothoracic Surgery, Heart Institute, Cincinnati Children's Hospital Medical Center, Cincinnati, Ohio.

Disclosures: The author reported no conflicts of interest.

The Journal policy requires editors and reviewers to disclose conflicts of interest and to decline handling or reviewing manuscripts for which they may have a conflict of interest. The editors and reviewers of this article have no conflicts of interest.

Received for publication Nov 3, 2021; revisions received Nov 3, 2021; accepted for publication Nov 5, 2021; available ahead of print Nov 10, 2021.

Address for reprints: Carl L. Backer, MD, Section of Pediatric Cardiothoracic Surgery, UK HealthCare Kentucky Children's Hospital, 800 Rose St, C-259, Lexington, KY 40536-0293 (E-mail: Carl.Backer@uky.edu).

J Thorac Cardiovasc Surg 2022;163:2229-30

$0022-5223 / \$ 36.00$

Copyright (c) 2021 by The American Association for Thoracic Surgery

https://doi.org/10.1016/j.jtcvs.2021.11.006
}

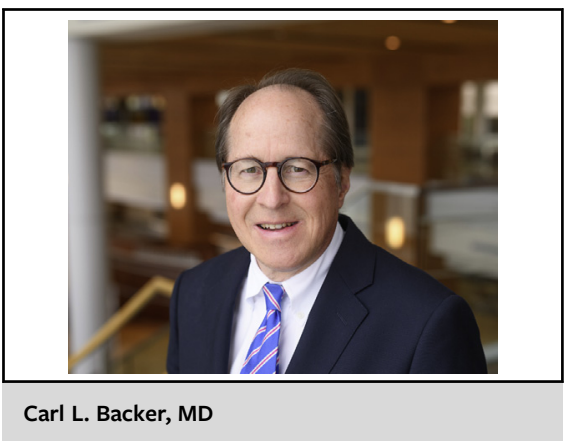

CENTRAL MESSAGE

Regionalization of care of infants

with tracheal stenosis to one

center led to a high volume of

slide tracheoplasty procedures

with focused surgical strategies

that led to excellent results.

simultaneous repair of the trachea and the associated pulmonary artery or intracardiac lesions. Their excellent results speak to the utility of this strategy.

The authors emphasize the timing of the surgery, a novel strategy for patients with a bridging bronchus, and fairly extensive use of anterior tracheopexy in properly selected patients. They also confirm the use of running everting suture technique with polydioxanone suture to decrease granulation tissue and provide a reliable airtight suture line. Only 2 patients in the series required reoperation for anastomotic dehiscence, and both survived.

The authors performed bronchoscopy-guided immediate anterior tracheopexy in selected children after the intraoperative anastomosis. The authors feel that this reduced the incidence of postoperative reintubation.

Regarding the bridging bronchus, the authors describe a clever technique where they transect the trachea at the lower edge of the first carina. They then cut a small opening in the right upper lobe bronchus along the anterior wall. The lower bridging bronchus is filleted open posteriorly and brought up (slide) as an onlay patch. This reconstructs the carina and also opens the right upper lobe bronchus. One finishes with essentially a trifurcated carina.

In conclusion, I would like to congratulate the entire cardiothoracic team at Shanghai Children's Medical Center for their excellent results in managing children with 
congenital tracheal stenosis who require a slide tracheoplasty. The regionalization of children to their center has led to a high volume of procedures, which has led to innovative strategies and truly excellent outcomes for these complex infants.

\section{References}

1. Tsang V, Murday A, Gillbe C, Goldstraw P. Slide tracheoplasty for congenital funnel-shaped tracheal stenosis. Ann Thorac Surg. 1989;48:632-5.

2. Chen L, Zhu L, Wang H, Lu Z, Xu Z, Du X, et al. Surgical management strategy of slide tracheoplasty for infants with congenital tracheal stenosis. J Thorac Cardiovasc Surg. 2022;163:2218-28.
See Article page 2218.

\section{Commentary: Slide tracheoplasty for congenital tracheal stenosis: Sliding by the missing pieces}

\author{
Anusha Jegatheeswaran, MD, PhD, FRCSC, ${ }^{\text {a }}$ and \\ Nagarajan Muthialu, FRCSEd ${ }^{\text {b }}$
}

Congenital tracheal stenosis (CTS) is a rare lesion that can have a spectrum of severity. Children with CTS often present early in life with symptoms, including wheezing, stridor, cyanosis, apnea, and recurrent pneumonia/upper respiratory tract infections. Although multiple strategies have been employed to tackle CTS, slide tracheoplasty was first described by Tsang and colleagues in 1989. ${ }^{1}$ Chen and colleagues ${ }^{2}$ describe their impressive 10-year experience with slide tracheoplasty in 120 infants with CTS, at a single center in Shanghai. Of note, this only accounted for a mere $26 \%$ of slide tracheoplasties done at Shanghai Children's Medical Center during the study period, which spanned from April 2010 to September 2020. Currently, slide tracheoplasty remains a challenging procedure for many, in part due to the infrequent treatment of this lesion at most centers and the common occurrence of complicating features. This is validated in this cohort, with $89 \%$ having a concomitant

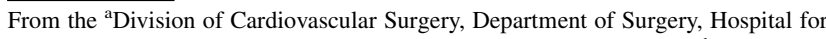
Sick Children, University of Toronto, Toronto, Ontario, Canada; and ${ }^{\mathrm{b}}$ Department of Cardiothoracic Surgery, Great Ormond Street Hospital for Children, University College London, London, United Kingdom.

Disclosures: A. Jegatheeswaran has received an honorarium for a lecture at the Cleveland Clinic Foundation on an unrelated topic. N. Muthialu reported no conflicts of interest.

Received for publication Dec 13, 2021; revisions received Dec 13, 2021; accepted for publication Dec 15, 2021; available ahead of print Dec 18, 2021.

Address for reprints: Anusha Jegatheeswaran, MD, PhD, FRCSC, Division of Cardiovascular Surgery, Department of Surgery, Hospital for Sick Children, University of Toronto, 555 University Ave, Toronto, Ontario M5G 1X8 Canada (E-mail: anusha. jegatheeswaran@utoronto.ca).

J Thorac Cardiovasc Surg 2022;163:2230-1

$0022-5223 / \$ 36.00$

Copyright $₫ 2021$ Published by Elsevier Inc. on behalf of The American Association for Thoracic Surgery

https://doi.org/10.1016/j.jtcvs.2021.12.021

\section{Check for updates}

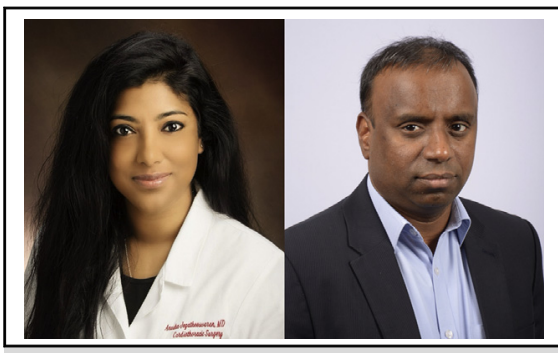

Anusha Jegatheeswaran, MD, PhD, FRCSC, and Nagarajan Muthialu, FRCSEd

CENTRAL MESSAGE

While a remarkably large study, additional details would have added greatly to our understanding of CTS patients. Instead, we wonder whether the authors have inadvertently slid by the missing pieces.

cardiovascular anomaly, 53\% abnormal arborization, and $47 \%$ long-segment stenosis with an additional $18 \%$ having diffuse stenosis. Although the subject matter is important and the article has the potential to make an extremely strong contribution to the body of literature, there are some significant limitations.

The primary objectives of this retrospective study were to determine the predictors of both a longer duration of intubation and death. The investigators found that the predictors of a longer duration of intubation included lower body weight, concomitant cardiovascular anomalies, and normal tracheobronchial arborization using multivariable analysis. Due to the limited number of deaths in the series $(n=6)$, only univariable analysis was performed, which demonstrated that the factors associated with death included low body weight, preoperative invasive ventilation, a longer cardiopulmonary bypass time, and the presence of granulation tissue. It should be noted that for all of the continuous variables, cut points were set based on maximizing the log-rank test 